\title{
How Effective is Financial Education?
}

\author{
Alison O'Connell
}

New Zealand has an international reputation for its early promotion of financial education and information. Governments in many other countries are now sponsoring financial education programmes in efforts to improve apparently low levels of financial literacy. But despite it being such a hot public policy topic, there has been little evaluation of the effectiveness of financial education.

A recent study for the Retirement Commission (O'Connell, 2007a) investigates how well financial education is being evaluated around the world. It examines the findings of some frequently cited evaluations and some newer studies in academic and policy-related literature from New Zealand, Australia, Canada, the UK and US. It finds that despite much optimism, a positive impact from financial education has not been unambiguously proven. We do not know what works best and why. The study suggests that evaluating the effectiveness of financial education can and should be improved, even though the evaluation of financial education is inherently difficult and the impact of any one programme probably can never be fully isolated.

This article summarises some key points from the study. The first section sets the context for the international attention given to financial education. It then discusses the mixed results from financial education evaluations. The reasons why such evaluations are inconclusive are then explored. The article ends with some implications for this year's Review of Retirement Income Policy, and an assessment of the effectiveness of financial education available to New Zealanders.

\section{Increasing attention on financial education}

'Financial education' is a term used around the world to refer to various methods used to increase an individual's financial understanding. Not all of these methods would be described as 'education' by educationalists. A financial education programme could be a retirement seminar at work, a budgeting workshop in the community, a website such as www.sorted.org.nz, or a school curriculum.

The result of the financial education is intended to be improved financial literacy or capability: people are better able to make informed decisions on their finances throughout life. Most countries use the term 'financial literacy'. The UK refers to 'financial capability', suggesting a more developed concept that emphasises financial actions over knowledge. But in practice, all financial education aims at the same ultimate goal, comprehensively defined by the OECD to include behaviour as well as skills improvement:

Financial education is the process by which financial consumers/investors improve their understanding of financial products and concepts and, through information, instruction and/or objective advice, develop the skills and confidence to become more aware of financial risks and opportunities, to make informed choices, to know where to go for help, and to take other effective actions to improve their financial well-being. (OECD, 2005 p.13)

Behaviour change may be the ultimate goal of financial education overall, but improvement in skills or knowledge can be a valid goal of a specific financial education programme. There is general agreement that financial literacy or capability is a broad concept - including financial goal-setting, budgeting, managing household cash flow, managing debt, saving and investing - because these are all linked in any individual's personal circumstances. But a single programme can focus on one issue (for example, budgeting) or can be more wide-ranging. 
Governments are developing national strategies for financial literacy in the UK, US and Australia. With the setting up of the Retirement Commission in 1993, and the introduction of its website Sorted in 2001, New Zealand has been ahead of the trend for governmentsponsored provision of broad financial education. Financial education programmes are not only sponsored by governments. Much of the academic literature from the US and Canada covers the recent growth in programmes run by local, university, employer and other communities.

Why is financial education now a public policy issue? It is seen as a way of improving levels of financial understanding, which are thought to be low in many countries. Financial education should, therefore, mitigate shared concerns that, for example:

- many people do not participate in financial services, so are missing out in some way: for example, people without bank accounts may have to pay more to administer their utility bills;

- there are very high levels of household debt, and people generally do not understand how much it costs to service that debt;

- people do not understand financial basics well enough to deal with the complexities of increasing financial responsibilities, especially for retirement savings and university education, which used to be carried more by government;

- where 'advice' is provided by financial services companies, it tends to focus on the products that are for sale, rather than personal finance more generally; further, it is only available to people who are in the market for those products.

Some commentators suggest that governments have a moral obligation to pay more attention to financial education because of policies shifting financial decision making onto the individual (e.g. Campbell, 2006). For example, the introduction in July 2007 of autoenrolment to KiwiSaver means that New Zealanders have to engage with saving, even if it is only to make the decision to opt out. The New Zealand government explicitly recognised that financial education would have to be stepped up as part of the package (Office of the Minister of Finance, 2005).

With so much government, private sector and not-for- profit attention and funding going towards financial education, it can only be expected that there will be increasing scrutiny of the value for money received.

\section{Mixed results from evaluations to date}

The evaluations of financial education programmes made to date are of three different types:

- First, there is evaluation built into a specific financial education programme, to identify how successful that programme has been. For example, studies have evaluated whether students who have taken a high school course in finance score higher on a financial test that those who have not, or whether people attending a retirement seminar save more as a result.

- Second, there is the evaluation of what impact financial education has had on the financial understanding of a population. National population surveys of financial literacy or capability have been carried out only in Australia, New Zealand and the UK. Time series of such surveys are not yet available, so no inference can be drawn on how financial education might improve population literacy levels.

- Third, there is evaluation of past experiments. This is the approach taken by most academic papers on the subject, which have been written mainly in the US. These experiments may have been set up for other purposes, but the data collected have proved convenient for researching the impact of financial education. Various associations are explored between having had some form of financial education and, for example, financial understanding (measured by correct answers given to financial questions) or financial behaviour (measured by the rate at which people are saving or their accumulated net worth). This type of analysis asks, in general terms, how effective financial education can be.

From the body of evidence, it does seem to be the case that:

- There is a low level of financial understanding, with the implication that it can be improved.

- Financial knowledge or capability is associated with higher age (although it is lower in the oldest age group), education, income and wealth. 
- People scoring highly on financial knowledge are probably more likely to be those doing the 'right' things to manage their finances.

However, taken together, these evaluations show some contradictory results, and leave some questions unanswered. For example:

- It is not always the case that financial education is associated with the 'right' financial behaviour or good financial literacy. For example, the providers of the 'Jump\$tart' financial education curriculum material in US schools cannot find evidence to say it is improving thrift or decision making around personal finances (Mandell, 2006). Pre-purchase credit counselling appeared, in a study by Hirad and Zorn (2001), to help prevent later default on home loans if carried out face to face, but not over the telephone.

- No study has proved education causes better financial literacy or better financial behaviour. Hilgert et al. (2003) find correlations between having financial knowledge and financial practices, but point out that the causality could flow either way, or in both directions (or there could be a third, unexplained factor at work). For example, it is not necessarily the case that, having learned about equities through a financial education initiative, you are then more likely to invest in them. It could be that having invested in some, you are then more likely to answer in a survey that you think you know about them.

- It is not clear how the benefits of improved financial literacy vary across the income distribution. Lusardi (2004) found that the positive effect of retirement seminars on financial wealth decreased steadily moving into higher quartiles of wealth. But the most affluent students have led recent improvement in financial knowledge in US high schools (Jump\$tart Coalition, 2006).

- The interplay of factors other than financial education that may also affect financial behaviour is not well understood. Attending retirement seminars appears to increase financial wealth, but then other things are just as much associated with higher wealth (for example, going to college or not smoking).

- Financial education may sometimes act in undesirable ways, or, at least, in ways that conventional financial wisdom would suggest are undesirable. Mandell (2006) reports that students seem to get more from financial education if they have participated in a stock market game. But then they say they would not be thrifty, perhaps because they think they can rely on stock investments. After a retirement seminar programme in the US, almost $7 \%$ of people with a goal of retiring at age 65 said they would increase that age target, but over $7 \%$ said they would lower it (Clark and d'Ambrosio, 2003).

The positive results of some studies give much cause for optimism that financial education is a good thing. But these contradictions and unknowns mean that we do not yet understand how well financial education works. We cannot assume that an intervention which worked in one situation will do so elsewhere. Enthusiastic claims of financial education being a panacea for all supposed financial ills need to be tempered with some evidence. Better evaluation of the effectiveness of different types of financial education would help to develop that evidence base.

\section{Why evaluation results are inconclusive}

Evaluating the effect of any education is difficult, and the success or otherwise of financial education is not easy to measure. This section considers four inherent difficulties with evaluating financial education programmes.

\section{Data integrity}

Inevitably, most data is collected through surveys or interviews with people about their personal finances. Such data has well-known difficulties:

- The data may be limited and biased. Some people will not divulge personal financial information, so people taking part in any survey form a self-selected group. Many studies using personal financial data look only at individual's holdings in one product or with one institution, so are unable to identify whether, for instance, even if retirement plan saving went up, other household saving went down.

- Most of the data is collected from people selfreporting their own financial understanding, capability or behaviour, without actual observations to prove that they do what they say they do. People are not always accurate about financial matters. In the Australian survey of financial literacy, $67 \%$ said they have an understanding of compound interest, 
but only $28 \%$ actually answered a question on it correctly (OECD, 2005).

- Data from different surveys is not comparable. Different data is collected in different surveys, although it may sound as if they are investigating the same issue. Surveys investigating how many people understand compound interest ask very different questions of different degrees of difficulty. Further, the 'right' answers to some financial literacy tests can seem trivial or misleading.

\section{Practical difficulties}

Collecting financial education evaluation data is often time-consuming, costly and difficult. Lyons et al. (2005) found that evaluation was considered difficult by the US community-based financial education practitioners interviewed and many of the educators felt they lacked the knowledge or time to do it well. Evaluation was often an afterthought, without sufficient management attention or strategic thinking being applied.

\section{Isolating the impact of a specific programme}

Even with a well-conducted survey, interpreting the results is not easy. The challenge lies in isolating the long-term impact of any specific financial education intervention, a task made difficult by the inherent nature of personal finances.

- Financial education programmes vary. A study looking at people who said they had attended a retirement seminar at some point in their career puts under the one heading of 'retirement seminar' many different types of teaching methods, subject matter and quality of material. Similarly, people who say they were exposed to some kind of consumer education at school will have studied a wide range of personal finance topics.

- No financial education programme works in isolation. Seemingly small encouragements from within a social network can make a relatively significant impact. Financial education may not work immediately, but take time, during which people are exposed to the powerful influences of family, friends, changes in life situation and legislative or tax changes. We do not know how all these other possible influences complement or compete with financial education initiatives.
- There is inherent, and unexplained, variation in individuals' financial behaviour. People appear more likely to say that they will make a change after financial education than they are actually to make a change. People make seemingly irrational financial decisions, even when presented with advice on what would be the best thing to do. Traditional economic theory does not explain the reasons for variation in financial behaviours, and newer behavioural economics does not yet complete the puzzle. So different people will act in different ways after financial education, and separating out how the education itself makes an impact will always be difficult.

\section{Putting the impact in context}

Even if the effect of a specific programme could be isolated, there is then the difficulty of comparing it to what it should be. There are many different desirable outcomes that financial education could have, but it seems to be difficult to put the results in a critical context of what should be expected.

- The goal of financial education is not yet clearly defined. So far, champions of financial education have tended to assume it must be beneficial and done as much as possible, within limited budgets. Precisely what the financial education is trying to achieve and how this should be measured have received less attention. There is a long list of what the impact of financial education programmes might be expected or desired to be: see Box 1 for examples. Perhaps because they are easier to measure, the aims at the top of this list - improving participation, financial knowledge and attitudes - tend to get measured more often than those in the middle and at the bottom of the list, to do with individual behaviour and macroeconomic impact. However, there is a strong case for increasing the emphasis on evaluating how people actually change their financial behaviour as a result of financial education, not least as causality from better financial understanding to making the right financial decisions is not proven.

- There are no benchmarks for what should be expected on any measure for any population. There has been no debate in the evaluations of financial education so far on what the appropriate level or amount on each measure should be. For example, what balance between debt and savings 
is the right one? In a survey of a population with a particular income distribution and cost of living, what proportion of people can be expected to have spent all their income at the end of the month? How many people should be able to answer a question on compound interest, or understand a superannuation statement, given the general levels of numeracy and literacy in the population? Assuming the goal of financial education is to improve these figures, what improvements are feasible? To get some idea of likely improvements it would be useful to compare data between populations, but the available data is piecemeal and far from being standardised.

Because of the practical, theoretical and conceptual difficulties of evaluating financial education programmes, it is unlikely that evaluation will ever be able to quantify absolutely the effectiveness of financial education. But still, given the increasing attention and funding being given to financial education, it can only be expected that the need to know whether financial education programmes are successful will increase.

Box 1: What is financial education trying to achieve?

- A target number of people receive generic financial advice?

- The level of financial knowledge, or capability, or confidence increases: generally across the population or in specific groups?

- People's attitudes towards finances improve, e.g. they become thriftier?

- People take some specific actions, e.g. make more retirement savings or pay down debt?

- People take action to improve their personal financial situation overall, e.g. a better balance of diversified savings and debt?

- Macroeconomic indicators improve, e.g. economic growth is stimulated as more people save more?

- The financial market becomes more efficient or the costs of regulation reduce as more financially literate consumers demand a better deal from product providers?

\section{Implications for New Zealand}

New Zealand has more years of experience in providing public financial education than other countries. It has done so on a small budget: NZ\$4.6m in 2005/6. Sorted has been used as a best-practice website for other countries, including the UK (NAO, 2007). The Retirement Commission's additional material to help New Zealanders with their response to KiwiSaver gives topical interest, highly relevant to the UK especially as it follows the auto-enrolled savings lead (O'Connell, 2007b).

New Zealand is one of three countries to have started national surveys on financial knowledge levels. It built on the experience from a similar survey in Australia. The UK's Financial Services Authority has taken - some may argue - a more sophisticated approach, but on the other hand, the New Zealand survey seems more practical and replicable.

So can New Zealand keep ahead? Financial education in schools has had perhaps less attention than in other countries, but it is getting established. New Zealand has not yet had a national strategy on financial literacy, but is developing one this year (Retirement Commission press release, 1 December 2006). 2007 is also a year for the retirement commissioner's Review of Retirement Income Policy, which this time includes an assessment of the effectiveness of financial education available to New Zealanders. This provides an opportunity for New Zealand to lead the way towards best practice evaluation.

Fox et al. (2005) suggested the use of a standard framework to improve evaluation technique. In concept the idea is very simple; what makes the difference is how it is tailored to each programme. The framework covers five questions, each of which should be considered for each programme to be evaluated, preferably while the programme is being designed:

1. Need: what objectives does the programme address?

2. Accountability: how much is the programme used and how much does it cost?

3. Fine-tuning: how could the programme be improved?

4. Micro-impact: how effective is the programme against its objectives?

5. Macro-impact: what impact is the programme having relative to the big policy picture? 
These questions would suggest the measurements and methods to be used in evaluation. Examples of the use of the framework are in O'Connell (2007a). Not every financial education initiative would necessarily need to answer every question, and some could emphasise the areas critical to the particular goal of that programme. The framework provides a discipline to think through what is relevant and important for any particular programme, and to balance that with the cost of carrying out the evaluation. Different programmes would therefore have different sets of measures and use different methods to collect the data relevant and useful to them, but working within a standard framework would allow comparisons.

The development of such a framework was supported by the international financial education experts who reviewed the Retirement Commission research study. Many of the difficulties with evaluating the impact of financial education should become easier by following the framework:

- It provides an external discipline where practitioners may not be experts in evaluation. It should save 'reinventing the wheel'. By the discipline of thinking through each tier of the framework, those designing the programme have to be clear on what it aims to teach people or how it aims to change behaviour. This should temper any tendency to think that any financial education must be a 'good thing'.

- The framework encourages tailoring within a standard. Individual programmes or sites such as schools can tailor their evaluation as they tailor their financial education programme. But working within a consistent standard should mean that comparisons across programmes are still valid. The most and least effective practices - within a programme or between different national or international programmes - would then be identified on consistent measures. The comparison would suggest ideas for how to improve those initiatives performing less well, and to what benchmark level it is realistic to expect improvements.

- The same framework could be applied to evaluate other financial well-being initiatives. Ideally, this could help to compare the effectiveness of different initiatives or policies. For example, it could help to develop a better picture of the relative value for money of financial education, tax incentives and auto-enrolment.

- Consistently applying the framework across initiatives and over time would mean that robust evidence is available when the value-for-money questions are asked. The evidence base should help keep the attention of policy makers and funding agents.

\section{Conclusion}

Despite much optimism, we simply do not yet know how effective financial education can be. Finding out is only going to become more important as more funding is directed towards improving 'financial literacy' or 'financial capability'. However, little evaluation is currently taking place and the evaluations made so far show mixed and inconclusive results. It is not clear whether this is a consequence of poor evaluation methods or poor programme design, or because financial education works patchily. But it does mean that a positive impact from financial education has not been unarguably proven; nor has a clear picture emerged of what works best and why.

Evaluation of financial education is inherently difficult, and the effect of any one programme can probably never be fully isolated. Nevertheless, evaluating the effectiveness of financial education can and should be improved. Further development of a standard framework would help. The difficulties of evaluation should not be used as an excuse not to evaluate. There may be some suspected benefits of financial education that can never be absolutely proven. But better evaluation of financial education programmes will improve our understanding of what helps people make good financial decisions.

Given New Zealand's history and international standing in financial education, it can take an international lead in developing techniques to understand better how effective financial education can be.

\section{References}

Campbell, J.Y. (2006) 'Household finance', Journal of Finance, 61 (4), pp.1553-604, available at www. blackwell-synergy.com

Clark, R.L. and M.B. d'Ambrosio (2003) 'Ignorance is not bliss: the importance of financial education', Research Dialogue, 78, available at www.tiaa-crefinstitute.org 
Fox J., S. Bartholomae and J. Lee (2005) 'Building the case for financial education', Journal of Consumer Affairs, 39 (1), pp.195-214, available at www.blackwellsynergy.com

Hilgert, M.A., J.M. Hogarth and S.G. Beverly (2003) 'Household financial management: the connection between knowledge and behaviour', Federal Reserve Bulletin, July, available at www.federalreserve.gov

Hirad, A. and P.M. Zorn (2001) 'A little knowledge is a good thing: empirical evidence of the effectiveness of pre-purchase homeownership counseling', paper presented at the Federal Reserve Bank of Chicago conference, March 2003, available at www.chicagofed. org/cedricl

Jump\$tart Coalition (2006) Improving Education: 2006 national Jump\$tart Coalition survey, available at www. jumpstart.org

Lusardi, A. (2004) 'Saving and the effectiveness of financial education', in O. Mitchell and S. Utkus (eds), Pension Design and Structure: new lessons from behavioral finance, New York: Oxford University Press

Lyons, A.C., L. Palmer, K.S.U. Jayaratne and E. Scherpf (2005) Are We Making the Grade? A national overview of financial education and program evaluation, working paper 012, Chicago: Center for Economic Education, University of Illinois, available at http:// cee.econ.uic.edu

Mandell, L. (2006) 'Financial literacy: if it's so important, why isn't it improving?', policy brief 2006-PB-08, Networks Financial Institute, Indiana State University, available at www.networksfinancialinstitute.org

National Audit Office (NAO) (2007) The Financial Services Authority, London: The Stationery Office, available at www.nao.org.uk/publications/nao_ reports/06-07/0607500.pdf

O'Connell, A. (2007a) Measuring the Effectiveness of Financial Education, Wellington: Retirement Commission, available at www.retirement.org.nz/ retirement_income_research_centre_home.html

O'Connell, A. (2007b) Submission to the Thoresen review of 'Generic financial advice', available from the author

OECD (2005) Improving Financial Literacy: analysis of issues and policies, OECD, available at www.oecd.org
Office of the Minister of Finance (2005) 'Memorandum to Cabinet Policy Committee: Budget 2005 savings package: work based savings scheme', 6 April, available at www.treasury.govt.nz

Alison O'Connell is an independent researcher and writer specialising in retirement income policy. Now based in New Zealand, she has worked as a UK actuary, strategy consultant and policy adviser at Westminster. She was most recently the founding director of the UK's Pensions Policy Institute. She can be contacted at alioc@dsl.pipex.com 